\title{
Activin signal transduction in the fetal rat adrenal gland and in human H295R cells
}

\author{
E Y Wang, E Y Ma and T K Woodruff ${ }^{1,2,3}$ \\ Department of Obstetrics and Gynecology, Feinberg School of Medicine, Northwestern University, Prentice 410, 333 E. Superior, Chicago, Illinois, USA \\ ${ }^{1}$ Department of Neurobiology and Physiology, Northwestern University, O.T. Hogan 4-150, 2153 N. Campus Dr., Evanston, Illinois, USA \\ ${ }^{2}$ Department of Medicine, Feinburg School of Medicine, Northwestern University, Chicago, Illinois, USA \\ ${ }^{3}$ Robert H Lurie Comprehensive Cancer Center, Northwestern University, Chicago, Illinois, USA \\ (Requests for offprints should be addressed to T K Woodruff, Department of Neurobiology and Physiology, Northwestern University, O.T. Hogan 4-150, 2153 \\ N. Campus Dr., Evanston, Illinois, USA)
}

The presence of activin A and its effects have previously been documented in the adrenal gland, particularly in the human fetal adrenal gland and the rat adrenal gland. The primary signaling pathway of activin involves interactions between receptor and intracellular (Smad) proteins that have not been completely described in the adrenal gland. In this study, we demonstrate that the components of the activin signaling cascade are present in two complementary models, the fetal rat adrenal gland and the human adrenocortical cell line, H295R, by means of RT-PCR, western analysis, and immunoprecipitation techniques. Using the cell line, activin signaling was analyzed using an activin-responsive reporter gene, p3TP-luc, and luciferase assays to assess transcriptional activity with co-expression of the different activin receptors and Smads to demonstrate the functionality of the signaling cascade.

In the fetal rat adrenal gland, the relative amounts of mRNA of the type II receptors, RII and RIIB, were regulated by gestational age, such that the RIIB levels increased after birth while RII levels fell. Using immunodetection techniques, the activin receptors and the different Smad proteins were detected in the rat fetal adrenal glands. Notably, the presence of Smad4 protein is significantly increased after birth in the rat adrenal gland. RT-PCR established a similar profile in the H295R cells. Using p3TP-luc, the H295R cells show transcriptional activation of this activin-responsive reporter in the presence of activin A. Co-expression of type I and type II receptors as well as Smads, results in ligand-independent transcriptional activity in addition to an activin-stimulated response. In determining activin's effects on adrenal function, adrenal steroid production was evaluated by incubation of the H295R cells with increasing doses of activin $\mathrm{A}$ and inhibin $\mathrm{A}$, resulting in a detectable increase in P450c17 expression. Co-incubation of activin A with follistatin diminishes this response.

These results are consistent with a role for activin A in the adrenal gland by demonstrating that the elements of the activin signaling pathway are present, intact, and functional. This suggests that in the adrenal gland the components of the activin receptor/Smad pathway are dynamically changing in the transition from fetal to neonatal life, and are important to the function of this organ.

Journal of Endocrinology (2003) 178, 137-148

\section{Introduction}

Activin $\mathrm{A}$ and inhibin $\mathrm{A}$ are members of the transforming growth factor $\beta$ (TGF $\beta$ ) superfamily. Activin $A$ is a homodimeric protein comprised of $\beta A$ subunits; a naturally occurring activin antagonist, inhibin $A$, is synthesized from the $\beta$ A subunit and an $\alpha$-subunit. TGF $\beta$ superfamily members are known to regulate numerous functions such as cell proliferation and differentiation, developmental patterning, and cell cycle arrest (Massague 1998). Converging lines of evidence suggest that activin is an important growth factor in pregnancy, such that activin probably acts as a paracrine factor until late in gestation when circulating levels of this hormone increase dramatically (Woodruff \& Mather 1995, Woodruff et al. 1997). Activin subunits are synthesized by the trophoblast cells (Petraglia et al. 1992) and activin binding occurs in pregnant myometrium and the adrenal gland (Draper et al. 1997). Alterations in activin levels have been associated with disease states such as pre-eclampsia (Muttukrishna et al. 1997, 2000, Grobman \& Wang 2000).

Activin may also be involved in the regulation of adrenal function during gestation. In mammals, the hypothalamic-pituitary-adrenal (HPA) axis of the fetus is crucial to organ maturation and parturition, such that disruption of the axis in fetal sheep results in prolonged gestation (Liggins et al. 1973), while anencephaly in humans is occasionally associated with postdatism (Challis \& Mitchell 1981). The actual factors involved in maturation of the fetal adrenal gland are as yet unclear; however, activin A and inhibin A have a role in this process. Activin and inhibin subunits have been detected in human fetal 
adrenal glands and in fetal zone cells (Spencer et al. 1992). Activin A induced inhibition of cell proliferation and upregulation of cortisol production in the presence of adrenocorticotropin (ACTH), while inhibin did not. Additionally, Spencer et al. (1999) have demonstrated that activin A induces apoptosis in fetal zone cells. After delivery, the fetal zone of the adrenal undergoes maximal apoptosis, leaving the definitive and transitional zones (DZ and TZ) to serve as the postnatal adrenal cortex. While the fetal zone primarily produces dehydroepiandrosterone sulfate (DHEAS), the TZ of the adrenal cortex produces cortisol, crucial to organ maturation in late gestation (Mesiano \& Jaffe 1997). Therefore, activin's actions upon the fetal adrenal are important to the maturation of this organ.

For a protein such as activin to exert an effect on a tissue or organ, a signal transduction pathway is necessary to convert the ligand's presence into alteration of gene expression by a cell. The initial cellular component of the activin/TGF $\beta$ signaling is the receptor complex comprised of type II receptors (RII or RIIB subtypes) which bind the ligand (activin), and the type I receptors (RI or RIB subtypes) which are phosphorylated by the type II receptor. This interaction of activin, type II, and type I receptors ultimately forms a heterotetrameric receptor complex (two RIIs+two RIs). The phosphorylated type I receptor, in turn, phosphorylates an intracellular protein known as a receptor Smad (Smad2 or Smad3). Subsequently, the phosphorylated (activated) receptor Smad will complex with a co-Smad (Smad4). The activated receptor Smad/ co-Smad unit translocates into the nucleus, where in conjunction with other transcription factors, it initiates activin/TGF $\beta$ responsive gene transcription (Derynck et al. 1998, Massague 1998). Smad6 and Smad7 are inhibitory Smads which interact with type I receptors to inhibit downstream activation of the cascade (Hayashi et al. 1997, Imamura et al. 1997). Another component of this system is the Smad anchor for receptor activation, or SARA protein, which recruits the receptor Smad, e.g. Smad2, to the type I receptor for future activation (Tsukazaki et al. 1998).

While it is clear that activin exerts an effect on the fetal adrenal gland, the mechanism by which this ligand acts has not been fully described. The rat model and the H295R cell line were chosen to investigate if the activin signal transduction cascade is present and functional in the fetal adrenal gland. Even though the rat adrenal gland does not replicate human adrenal steroidogenesis and development, the fetal adrenal gland in the rat, as in the human and other mammalian species, must upregulate the production of corticosteroid to contribute to lung, brain, and gut maturation via expression of $\mathrm{P} 450$ enzymes during the late days of gestation (Mitani et al. 1997). Rat pregnancy can easily be followed longitudinally allowing for identification of in vivo evidence of signaling components in the fetal organs, i.e. naturally occurring factors not induced by in vitro overexpression. A cell line is useful in studying the effect of separate signaling components in effecting transcription, which is difficult to evaluate in the whole animal. The H295R cell line is capable of producing each of the zone-specific steroid classes, acting much like human fetal adrenocortical cells (Rainey et al. 1994). Ultimately, the aim of these studies is to understand the activin signaling pathway in the context of the human fetal adrenal gland. Therefore, this cell line allows for in vitro studies using human-derived cells. Using these complementary approaches, activin receptors and intracellular signaling Smad proteins have been identified in adrenal cells and tissues in the context of functional activation.

\section{Materials and Methods}

\section{Materials}

Recombinant activin A and inhibin A were produced at Northwestern University, Evanston, IL, USA. The ligands were formulated in a buffer of $0.15 \mathrm{M} \mathrm{NaCl}$ and $0.05 \mathrm{M}$ Tris, $\mathrm{pH} 7 \cdot 4$. Antibodies were obtained from the following: anti-RII and anti-RIIB antisera courtesy of K Mayo (Evanston); anti-RI and RIB antibodies from R\&D Biosystems (Minneapolis, MN, USA); antibodies against Smad2, Smad3, and Smad4 from Santa Cruz Biotechnologies (Santa Cruz, CA, USA), from Transduction Laboratories (Lexington, KY, USA), and courtesy of Dr Peter ten Dijke (Amsterdam, The Netherlands); anti-phosphoserine antibody from Zymed Laboratories (San Francisco, CA, USA); P450c17 antibody courtesy of W Miller (San Francisco, CA, USA); and P450c21 antibody courtesy of A Payne (Stanford, CA, USA).

\section{Animals and tissue harvest}

Timed pregnant Sprague-Dawley rats $(n=3-5$ for gestational ages days $17-21$, each with 8 or more pups) and litters of neonatal rats $(n=15)$ on day 1 and 2 of life (Harlan Biosciences, Indianapolis, IN, USA) were maintained on a $14 \mathrm{~h}$ light/10 h darkness schedule with constant access to food and water before and during the study. The animals were narcotized with $\mathrm{CO}_{2}$ and killed. Fetal/neonatal adrenal glands were removed and frozen on dry ice with storage at $-80{ }^{\circ} \mathrm{C}$. All animal experimentation was conducted in accordance with the NIH Guide for Care and Use of Laboratory Animals and approved by the Northwestern University Animal Care and Use Committee.

\section{NCI-H295R cell line}

Human NCI-H295R adrenocortical tumor cells were obtained from the American Type Culture Collection (Rockville, MD, USA). Cells were maintained in 
Table 1 Primer sequences

\begin{tabular}{|c|c|c|c|}
\hline & Primer & Primer sequence & PCR fragment $(\mathrm{bp})$ \\
\hline \multicolumn{4}{|l|}{ Gene } \\
\hline \multirow[t]{2}{*}{$\mathrm{RI}$} & 5'primer & TTATCATGAAATGGGATCGTTGTACG & 648 \\
\hline & 3'primer & TTGGTCAAAGTCTTTTTGATACGCAG & \\
\hline \multirow[t]{2}{*}{ RIB } & 5'primer & САСТGACTACTGCAACAGGATCGAC & 280 \\
\hline & 3'primer & CССTGAGGTGGAGAGATCGTAGAC & \\
\hline \multirow[t]{2}{*}{ Smad2 } & 5'primer & СCAGGAATTTGСTGСТСТTC & 322 \\
\hline & 3'primer & TCCATAGGGACCACACACAA & \\
\hline \multirow[t]{2}{*}{ Smad3 } & 5'primer & GGCTCССTCATGTCATCTACT & 433 \\
\hline & 3'primer & AGTAGGTAACTGGCTGCAGGT & \\
\hline \multirow[t]{2}{*}{ Smad4 } & 5'primer & TGATCGATATGGACAATATGTCTAT & 700 \\
\hline & 3'primer & TGGTGCTGAAGATGGCCGTT & \\
\hline \multirow[t]{2}{*}{ Smad6 } & 5'primer & AAGCCACTGGATCTGTCCGATT & 581 \\
\hline & 3'primer & GGTGATGAACTGCCGGGAGTA & \\
\hline \multirow[t]{2}{*}{ Smad7 } & 5'primer & TGTGTTGCTGTGAATCTTACGGG & 398 \\
\hline & 3'primer & ССАGСТGАСТСТTGTTGTCСGA & \\
\hline \multirow[t]{2}{*}{ SARA } & 5'primer & АGTССТСТАССАGСАGAGACGGATATT & 662 \\
\hline & 3'primer & GAATAGTGGGCATGGATAAAGTCGATA & \\
\hline \multirow[t]{2}{*}{ GAPDH } & 5'primer & GTTCCAATATGATTCCAC & 228 \\
\hline & 3'primer & GAGATGATGACCCTTTTG & \\
\hline
\end{tabular}

DMEM:F12 media supplemented by $15 \mathrm{mM}$ HEPES, $0.00625 \mathrm{mg} / \mathrm{ml}$ insulin, $0.00625 \mathrm{mg} / \mathrm{ml}$ transferrin, $6.25 \mathrm{ng} / \mathrm{ml}$ selenium, $1.25 \mathrm{mg} / \mathrm{ml}$ bovine serum albumin, $0.00535 \mathrm{mg} / \mathrm{ml}$ linoleic acid, $97.5 \%$, and $\mathrm{Nu}-$ Serum I, $2 \cdot 5 \%$ (BD Biosciences, Bedford, MA, USA). Cells were incubated in $95 \%$ air and $5 \% \mathrm{CO}_{2}$.

\section{$R N A$ extraction and $R T-P C R$}

Total RNA was extracted from pooled individual adrenal glands $(n=6-8)$ or from H295R cells using the method of Chomczynski \& Sacchi (1987), using GTC and acid phenol for extraction. Total RNA $(5 \mu \mathrm{g})$ was reverse transcribed into cDNA using random oligonucleotides. Samples with no reverse transcriptase $(-\mathrm{RT})$ and $\mathrm{H}_{2} \mathrm{O}$ were used as controls for DNA contamination. cDNA was amplified by PCR with an annealing temperature of $55{ }^{\circ} \mathrm{C}$. The PCR products were separated by electrophoresis on an agarose gel containing ethidium bromide and visualized under UV light. The specific PCR primers used and the predicted fragment sizes are shown in Table 1.

\section{Real-time RT-PCR}

Oligonucleotides and TaqMan probes were used on an ABI PRISM 7700 Sequence Detector (Perkin-Elmer Applied Biosystems, Foster City, CA, USA). Two dyes are covalently linked to the TaqMan probe, one at the $5^{\prime}$ end (FAM, 6-carboxy-fluorscein) and one at the $3^{\prime}$ end (TAMRA, 6-carboxy-tetramethyl-rhodamine). Since fluorescent quenching depends on spatial proximity of the two dyes, FAM is quenched by TAMRA when the probe is intact. The RT-PCR reaction was performed in 96 sample tubes per assay ( $25 \mu \mathrm{l}$ per tube) in a reaction buffer containing $1 \times$ TaqMan EZ buffer, $3 \mathrm{mM} \mathrm{Mn}(\mathrm{OAc})_{2}$, $300 \mathrm{mM} \mathrm{dA} / \mathrm{dC} / \mathrm{dG} / \mathrm{dUTP}, 2.5$ units $\mathrm{rTth}$ DNA polymerase, $200 \mathrm{nM}$ primers (forward and reverse), $100 \mathrm{nM}$ TaqMan probe, and $100 \mathrm{ng}$ total RNA. RT reaction conditions were $55^{\circ} \mathrm{C}$ for $50 \mathrm{~min}, 60^{\circ} \mathrm{C}$ for $10 \mathrm{~min}$, and $95{ }^{\circ} \mathrm{C}$ for 2 min for 1 cycle; PCR conditions were $95{ }^{\circ} \mathrm{C}$ for $15 \mathrm{~s}$, and $58{ }^{\circ} \mathrm{C}$ for $1.5 \mathrm{~min}$ for 40 cycles. The receptor specific primers and probes are listed in Table 2.

Target mRNA content in samples, such that two to three different sets of pooled adrenal RNA per age group were run in triplicate, was measured simultaneously in one assay run according to the manufacturer's protocol. Standards were generated using in vitro transcribed standard RNA and a nonpregnant ovarian mRNA preparation. The activin receptor RII and RIIB mRNA abundance was measured with respect to these standards.

\section{Immunohistochemistry}

Fetal and neonatal adrenal glands were frozen in OCT (Sakura Finetek, Torrence, CA, USA), sectioned at $12 \mu \mathrm{m}$ using a cryostat and fixed in ice-cold acetone. The primary RII or RIIB antisera and preimmune rabbit sera were diluted in PBS at a $2 \%$ concentration, and the sections were incubated overnight at room temperature, washed, incubated with a biotinylated goat anti-rabbit secondary antibody at 1:2500-1:5000 dilutions (Vector Laboratories, Inc., Burlingame, CA, USA), washed, and incubated in $A B C$ reagent (Vectastain $A B C$ kit, Vector Laboratories, Inc.). The signal was detected using the DAB (3,3'-diaminobenzidine) substrate kit (Vector Laboratories, Inc.), and sections were counterstained with 
Table 2 TaqMan primer and probe sequences

\begin{tabular}{|c|c|c|}
\hline & Primer/Probe & Sequence \\
\hline \multicolumn{3}{|c|}{ Gene } \\
\hline \multirow[t]{3}{*}{ RIIB } & 5'primer & GCTCACGGTGCTGGCCTA \\
\hline & 3'primer & AGGCCAGCAGGACGATGA \\
\hline & Probe & 6-FAM-CGCTGCTGCCCATTGGAGGC-TAMRA \\
\hline \multirow[t]{3}{*}{ RII } & 5'primer & ССТАСТАСААСАТССТGСТGTАТTСС \\
\hline & 3'primer & AGTACAGGAGGGTAGGCCATCTT \\
\hline & Probe & 6-FAM-ATTGTCATTTGTGCGTTTGGGTGTACAGA-TAMRA \\
\hline
\end{tabular}

hematoxylin. Negative control sections were incubated with non-biotinylated secondary antibody as a primary antibody.

\section{Immunoprecipitation and western blot for Smad proteins and} for P450c17 and P450c21

Adrenal lysates were made from the frozen adrenal glands, pooling 6-8 adrenal glands per sample, using RIPA buffer (50 mM Tris, pH 7.5, $150 \mathrm{mM} \mathrm{NaCl}, 1 \mathrm{mM}$ EDTA, $0.5 \%$ deoxycholic acid, $0 \cdot 1 \%$ sodium dodecyl sulfate (SDS)) and protease inhibitors (Roche, Indianapolis, IN, USA). Antibodies were coupled to protein $A / G$ beads (Pierce Chemical Company, Rockford, IL, USA). Lysates were clarified by centrifugation. Using a Bradford assay (Bio-Rad, Hercules, CA, USA) to quantify total protein, equal protein samples of adrenal lysates $(75-100 \mu \mathrm{g})$ were incubated with the antibody-coated protein beads or analyzed by SDS-polyacrylamide gel electrophoresis (SDS-PAGE on $10 \%$ acrylamide gel). Samples for western analysis were reduced and heated at $100{ }^{\circ} \mathrm{C}$ for $5 \mathrm{~min}$. Gels were transferred to nitrocellulose membranes and were blocked with $5 \%$ nonfat dry milk overnight at $4{ }^{\circ} \mathrm{C}$. Tris-buffered saline with $0 \cdot 1 \%$ Tween was used to wash the membranes. Primary antibody dilutions ranged from 1:100-1:1000 depending on the different antibodies or antisera. The secondary antibody was used at 1:2000 to 1:5000 dilutions.

Blots were developed with ECL chemiluminescence reagents (Amersham Pharmacia Biotech, Piscataway, NJ, USA). Densitometric analysis was performed using a Macintosh computer and the public domain NIH Image program (developed at the US National Institutes of Health and available on the Internet at http:// rsb.info.nih.gov/nih-image/).

\section{Transfection studies}

The p3TP-luc reporter plasmid was provided by the $\mathrm{J}$ Massague laboratory (New York City, NY, USA). Activin receptor (type I, IB, II, IIB) expression plasmids were provided by L Mathews (Ann Arbor, MI, USA) and K Mayo. The GAL4 response element-luciferase reporter and GAL4-Smad constructs were provided by W
Schnaper (Chicago, IL, USA). The pRL-TK Rluc reporter vector was obtained from Promega Corp. (Madison, WI, USA).

H295R cells were plated prior to transfection in 12well plates and allowed to grow to $70-80 \%$ confluence. The cells were transiently co-transfected with p3TP-luc or GAL4-luciferase reporter, and various expression plasmids encoding different activin receptors, Smads, or empty pcDNA3 vector (Invitrogen Corporation, Carlsbad, CA, USA) using the Lipofectamine Plus method (Invitrogen Corp.). After overnight recovery in fresh growth medium, cells were treated with the indicated ligands for $24 \mathrm{~h}$ in Opti-MEM (Gibco, Invitrogen Corp.). Cells were washed in PBS and lyzed in Triton X-100 and luciferase activity was measured using an AutoLumat LB953 luminometer (Berthold Technologies, Oak Ridge, TN, USA). Total protein was determined using BCA reagent (Pierce Chemical Company). Luciferase activity was normalized to the amount of protein in each extract. At least three replicates were performed per treated ligand in each experiment. Each experiment was repeated a minimum of three times.

Alternatively, co-transfection of p3TP-luc, expression plasmids, and the pRL-TK Rluc reporter was performed. Cells were treated and then assayed using the DualLuciferase Reporter system (Promega). The relative light units (RLUs) were normalized to the light units expressed by the Renilla luciferase. At least three replicates were performed per treated ligand in each experiment. Each experiment was repeated a minimum of three times.

\section{Statistical analysis}

Values are expressed as means \pm one standard deviation (S.D.). Data were assessed for normality using the Kolmogorov-Smirnov test. With data where normality was not achieved, the data were analyzed with nonparametric methods, such as the Mann-Whitney test and the Kruskal-Wallis test, with a subsequent post-hoc test using least significant difference between mean ranks. Statistical comparison between control and treatment groups for the luciferase assays were made by one-way analysis of variance (ANOVA) with Tukey's test as a post-test to evaluate 

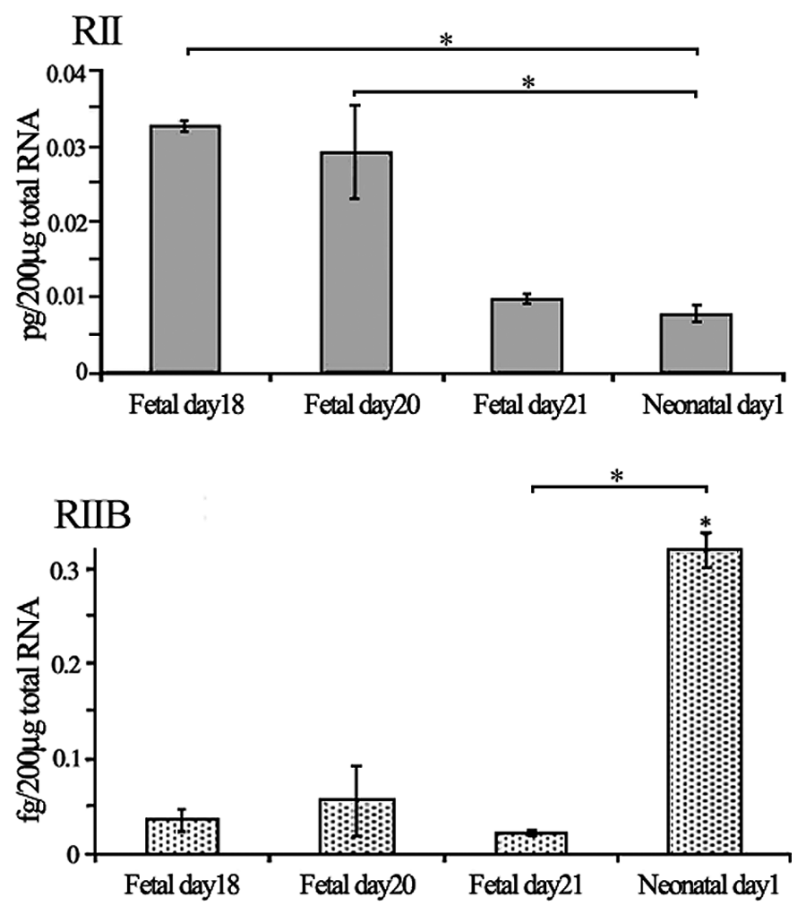

Figure 1 Real-time RT-PCR data illustrating the relative quantities of activin type II receptor mRNA. RII and RIIB expression was quantified from total pooled rat adrenal gland RNA (fetal days 18, 20,21 , and neonatal day 1). RNA was extracted from fetal adrenal glands from pups of the same litter with subsequent real-time RT-PCR as described in Materials and Methods. Data are presented as means \pm S.D. for each age group with analysis by the Kruskal-Wallis test and post-tests to determine significant differences between pairs of means. ${ }^{*} P<0 \cdot 05$.

the means of specific treatment pairs or with unpaired Student's $t$-test when applicable. Significance was assumed at $P<0 \cdot 05$.

\section{Results}

The fetal and neonatal rat adrenal glands have the capacity to bind activin with expression of type II activin receptors

To determine if the fetal rat adrenal gland expressed the type II receptors, fetal rat adrenal RNA of specific gestational ages was subjected to real-time RT-PCR. Activin type II and type IIB receptor mRNAs were detected in late gestational and early neonatal adrenal glands. The real-time RT-PCR allowed for quantitative study of the type II receptor expression, using specific probes and primers listed in Table 2, in relation to the age of the fetal adrenal gland. The amount of RII mRNA is elevated in fetal day 18 adrenal tissue and notably decreases between day 20 and day 21 of fetal life, with delivery occurring on day 21. The RII expression in the day 18 adrenal gland is more than threefold greater than expression on day 21 (Fig. 1). RIIB mRNA content is low and

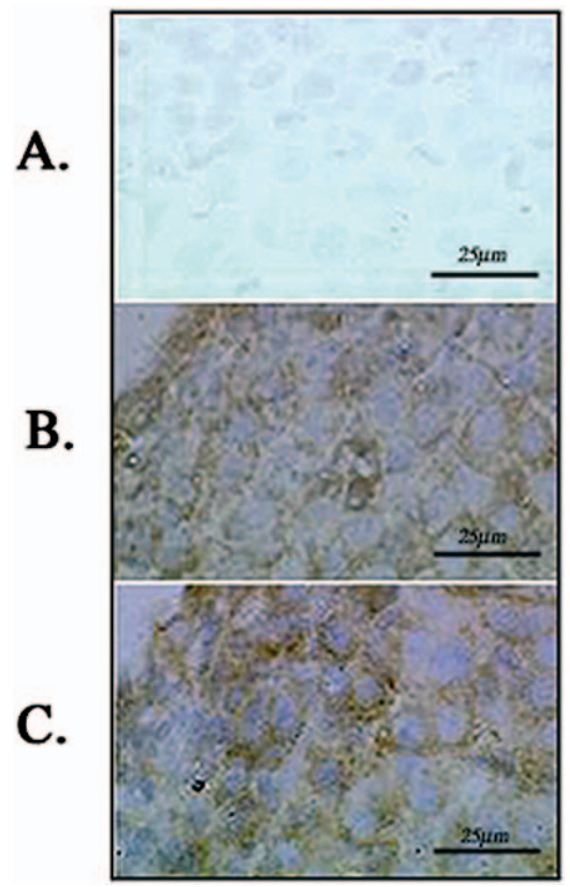

Figure 2 Expression of activin receptor RII and RIIB proteins in late gestational fetal rat adrenal glands. The panels are representative images at high magnification $(100 \times)$ of immunohistochemically treated day 18 rat adrenal sections (A) without primary antibody as a negative control, (B) with anti-RII antiserum and (C) with anti-RIIB antiserum. The presence of the detected proteins is indicated by the DAB (3,3'-diaminobenzidine) or brown staining.

relatively constant in the fetal rat adrenal gland (days 18-21) but is significantly elevated in neonatal day 1 adrenal samples, such that the amount of RIIB expression on neonatal day 1 is greater than five times the expression on day 20 and over ten times greater than day 21 expression (Fig. 1).

In H295R cells, RII mRNA and RIIB mRNA were also shown to be present by RT-PCR (data not shown), confirming the findings recently reported by Vanttinen et al. (2002).

To establish whether RII and RIIB proteins were present, immunohistochemistry of the fetal rat adrenal glands from day 18-21 fetuses was employed (Fig. 2). RII and RIIB were detected in the cortex of day 21 adrenal glands with RIIB staining being more discrete, i.e. minimal staining for RIIB was seen in the very outer perimeter of the gland below the capsule (data not shown).

The type I activin receptors and Smads are present and functionally available for activin signal transduction in fetal rat adrenal glands

Since the ligand-binding component of the receptor complex exists in fetal adrenal tissue, it was necessary to 

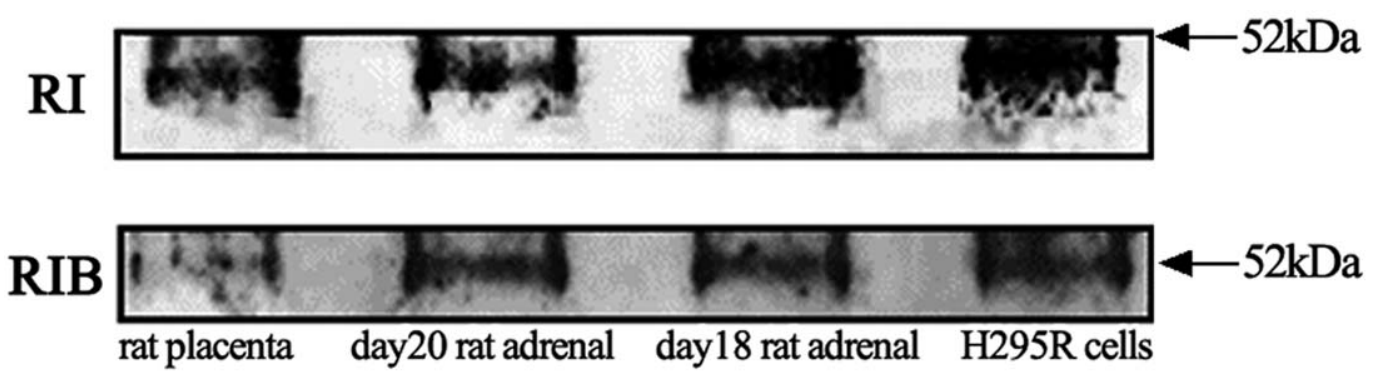

Figure 3 Expression of type I receptor proteins in rat placenta, fetal rat adrenal glands (day 20 and day 18), and the H295R human adrenocortical cell line. The RI (top panel) and RIB (bottom panel) proteins are detected in the rat tissues and in the human cell line. Tissue and cell lysates were subjected to immunoprecipitation with anti-RI or anti-RIB antibodies and visualization by immunoblotting with the same antibodies.

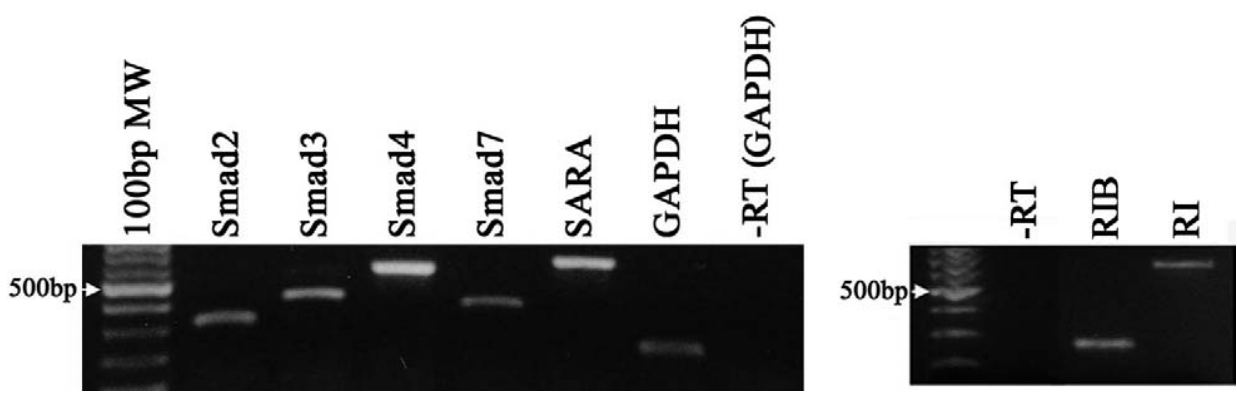

Figure 4 Expression of various Smad mRNAs, SARA mRNA, and activin type I receptor mRNAs in H295R cells. (Left panel) Representative RT-PCR of mRNA for Smad2, Smad3, Smad4, and Smad7, SARA, and GAPDH in H295R cells. (Right panel) Representative RT-PCR of mRNA for RIB and RI in H295R cells. Total RNA $(0.5 \mathrm{~g})$ from H295R cells was reverse transcribed and PCR amplified. PCR primers and fragment sizes are listed in Table 1.

document the presence of the type I activin receptors, crucial proteins linking initial activin binding to downstream intracellular signaling. Protein lysates were prepared from late gestational fetal rat adrenal glands, human adrenocortical H295R cells, and rat placenta. These lysates were then subjected to immunoprecipitation using anti-RI and anti-RIB antibodies. The RI and the RIB proteins in the fetal rat adrenal glands, in the H295R cell line, and in the rat placenta, were present and of similar molecular weight as seen in Fig. 3. The type I receptor contains core polypeptides of 500 to 570 amino acids (Massague 1998). The RI and RIB were also detected by western analysis of fetal rat adrenal gland lysates (data not shown).

To establish the expression profile of Smads involved in known intracellular activin/TGF $\beta$ signaling, both fetal rat adrenal glands and human H295R cells were studied at the mRNA level by using RT-PCR techniques with sequence-specific primers (Table 1) and at the protein level by using anti-Smad antibodies for western and immunoprecipitation analysis. Using RT-PCR, Smad2, Smad3, Smad4, Smad7, and SARA mRNAs (as well as the type I receptor mRNAs) were detected from the H925R cell line with representative data shown in Fig. 4. Smad6 mRNA was also detected (data not shown).

Smad2, Smad3, and Smad4 mRNA were present by RT-PCR analysis of the fetal rat adrenal total RNA (data not shown). The receptor Smad proteins, Smad2 and Smad3, and Smad4 (co-Smad) were detected by both immunoprecipitation and western analysis in the fetal rat adrenal glands (Fig. 5A, B, and C). Since Smad2 and Smad3 share greater than $90 \%$ sequence identity (Zawel et al. 1998) and are detected by the same antibody, it was necessary to use a specific Smad3 blocking peptide prior to immunoprecipitation to show the selective disappearance of the Smad3 band (Fig. 5B). Smad4, the co-Smad necessary for translocation of the signal into the nucleus to alter transcription, appears to be differentially expressed as the rat adrenal gland matures, with increased protein expression in the adrenal after birth (Fig. 5C).

If activin signal transduction is operating in the adrenal cells, activation of the receptor Smads will occur after activin binding by the receptor complex, and the subsequently phosphorylated Smads will be detectable. Immunoprecipitation of the fetal adrenal lysates with an anti-Smad2/3 antibody and with an anti-phosphoserine 
A. B.

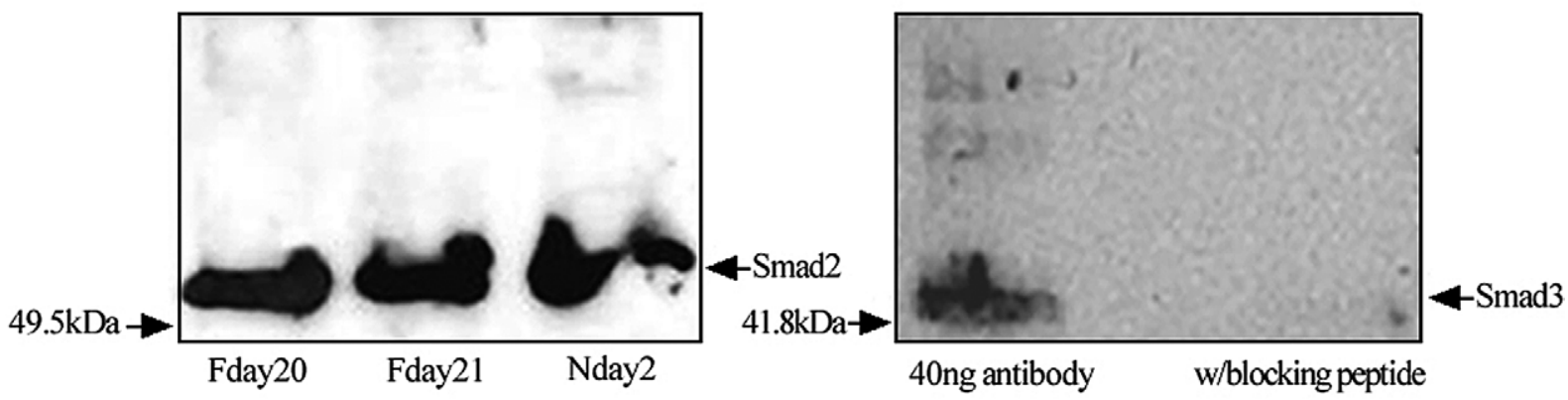

C.

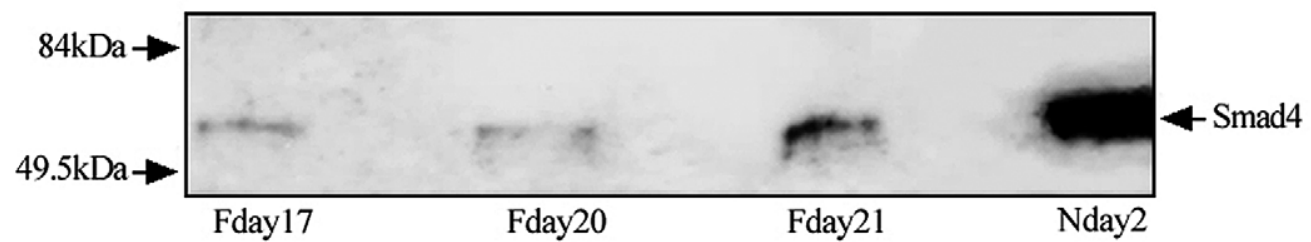

D.

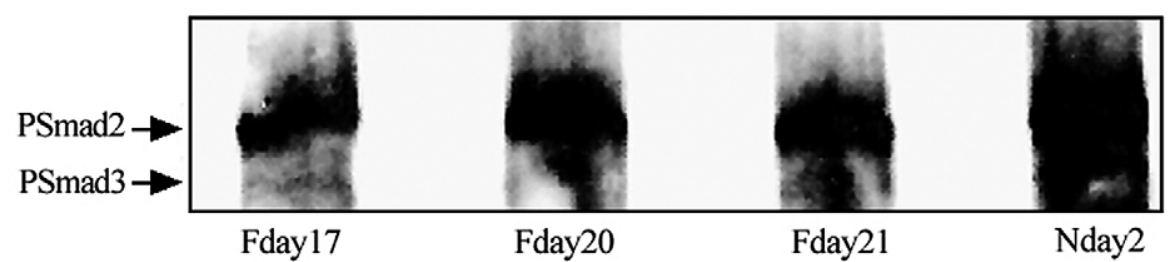

Figure 5 Expression of Smad proteins in fetal and neonatal rat adrenal glands. (A) Representative western analysis for Smad2 protein in rat adrenal lysates from fetal (F) days 20 and 21, and neonatal (N) day 2. Lysates were subjected to SDS-PAGE and a Smad2 specific antibody was used. (B) Immunoprecipitation of day 21 fetal adrenal lysate with identification of Smad3 protein. A Smad2/3 antibody was used for immunoprecipitation after preincubation with a specific Smad3 blocking peptide or vehicle. With the blocking peptide, the Smad3 band disappears (right lane) indicating the specific presence of Smad3 protein. (C) Representative immunoprecipitation for Smad4 from rat adrenal lysates (fetal days 17, 20, 21, and neonatal day 2). (D) Immunoprecipitation of a phosphorylated Smad2 and Smad3 in the adrenal lysates from fetal days 17, 20, and 21, and neonatal day 2 animals. An anti-Smad2/3 antibody was used for immunoprecipitation followed by detection with an anti-phosphoserine antibody.

antibody identified phosphorylated receptor Smads, primarily Smad2 (Fig. 5D).

Activin receptors and Smads are able to simulate transcriptional activation in $\mathrm{H} 295 \mathrm{R}$ cells

To determine if the components of the activin signaling pathway are functional and effect transcription in adrenal cells, an activin/TGF $\beta$ responsive reporter, p3TP-luc, was utilized to assess transcriptional activation in the presence of type II and type I activin receptors. In the absence of transfected receptors, there is basal stimulation of p3TPluc by activin (Fig. 6A). The H295R cells can produce activin $\mathrm{A}$, which can stimulate basal luciferase activity, but can be inhibited by the addition of follistatin (Fig. 6B).
With transient transfection of different type I and type II receptors with p3TP-luc, notable ligand-independent luciferase activity is present with the RI and RIB transfections (Fig. 6C). Activin stimulates luciferase activity in the presence of RI and RIB, with greater than 2-fold and 3-fold differences respectively, demonstrating activation of the activin signaling pathway in these cells.

Experiments with RII and RIIB show 3-fold and $1 \cdot 5$-fold activation respectively after incubation with $10 \mathrm{ng} / \mathrm{ml}$ activin A, with little ligand-independent stimulation (Fig. 6C). The lack of ligand-independent stimulation with the type II receptors highlights the relative importance of the type I receptors, such that when the type I receptors are overexpressed, Smad activation is still 
possible, bypassing activin binding. Transient transfection of the activin receptor complex (different combinations of the type I and type II receptors) results in ligandindependent luciferase activity (Fig. 6A). In the presence of activin, there is significant transcriptional activity when compared with the ligand-independent state, again indi- cating the functional activity of the intact activin signaling pathway in the adrenocortical cell, with the greatest activin-stimulated activity with RIB/RII.

To further understand activin signal transduction in the adrenal cell, GAL4 DNA binding domain-Smad constructs with a GAL4 response element luciferase reporter

A.

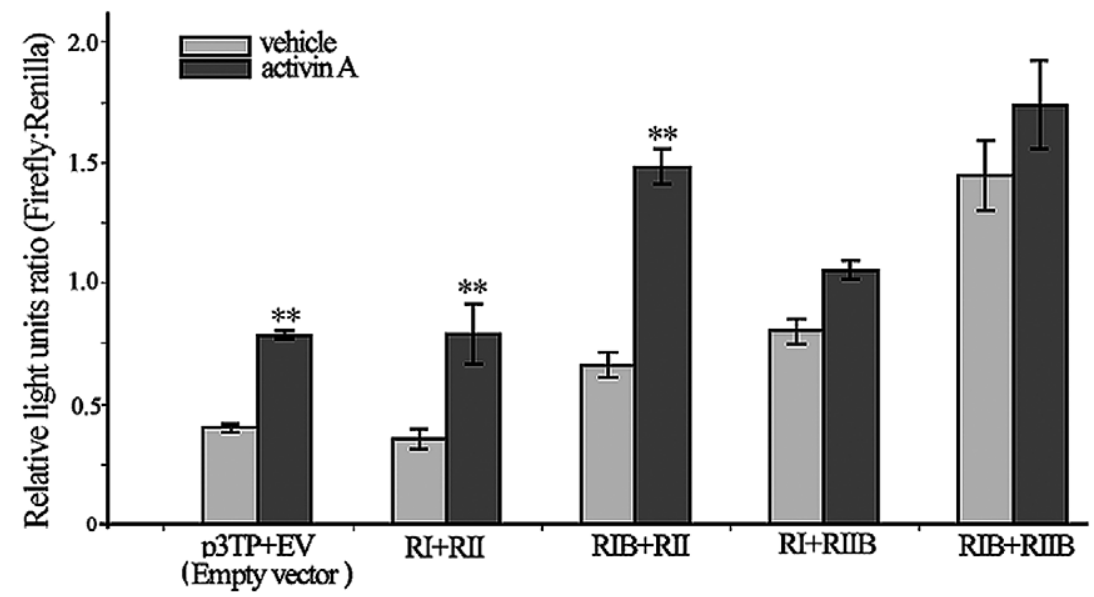

B.

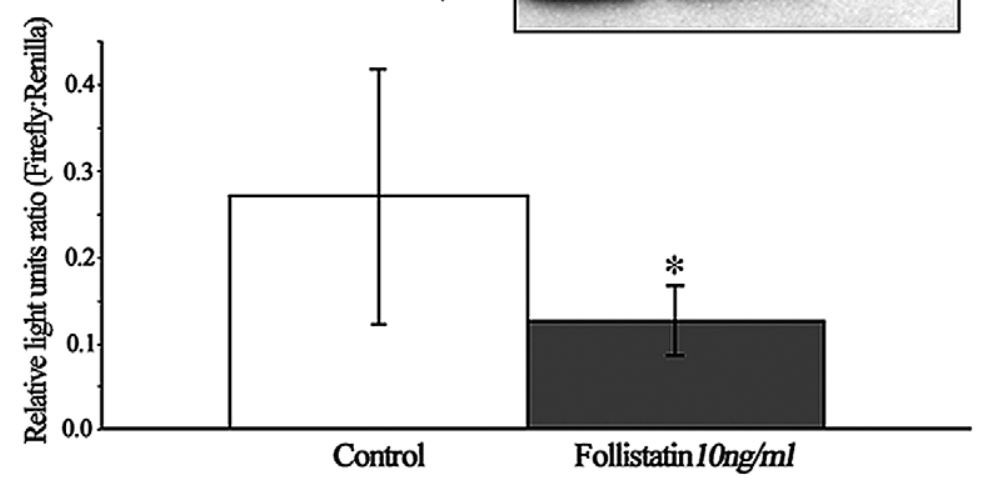

C.

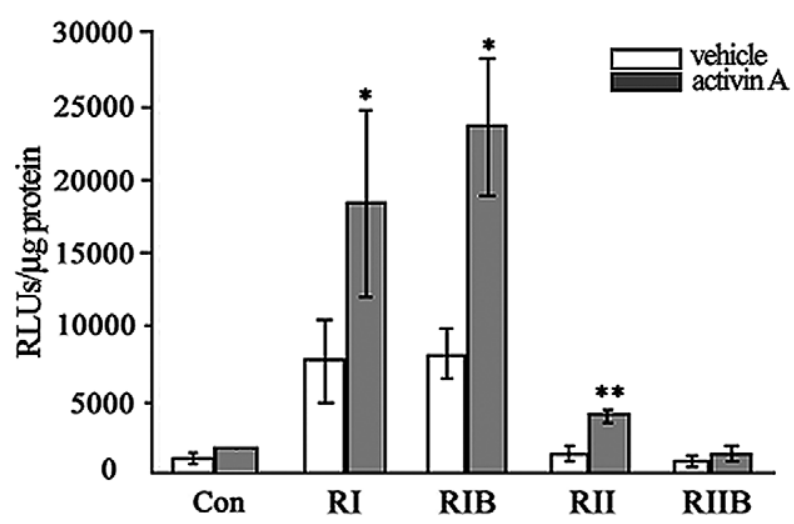




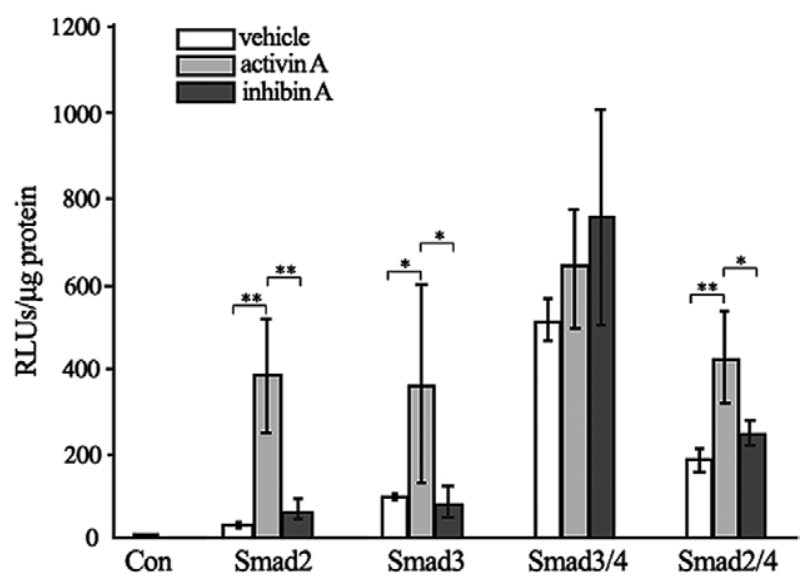

Figure 7 Activin A, inhibin A, and Smad stimulation of reporter gene transcriptional activity in $\mathrm{H} 295 \mathrm{R}$ cell. Smads stimulate ligand-independent activation of a GAL4 response element reporter gene, but this transcriptional activity is significantly increased in the presence of activin but not inhibin. H295R cells were transfected with GAL4 reporter along with the indicated GAL4 DNA binding domain-Smad constructs. The total amount of transfected DNA for each treatment group was kept constant. Transfected cells were cultured with vehicle, activin A, or inhibin A at $10 \mathrm{ng} / \mathrm{ml}$ for $24 \mathrm{~h}$ with measurement of relative luciferase activity as described in Materials and Methods. Data were normalized to the total amount of protein and are expressed as the mean \pm S.D. of triplicate samples from a representative experiment. The control bar represents luciferase activity after transfection of the reporter alone and incubation with vehicle. No difference in luciferase activity was seen with the reporter alone and activin A or inhibin A (data not shown). One-way ANOVA with post-test assessment was performed. ${ }^{*} P<0 \cdot 05,{ }^{*} P<0 \cdot 01$.

(GAL4-DNA binding element upstream of a minimal promoter) were used to detect Smad signaling in the H295R cells. Transfection of GAL4-Smad2 and GAL4Smad3 with subsequent $24 \mathrm{~h}$ incubations with activin A $(10 \mathrm{ng} / \mathrm{ml})$ resulted in a greater than ninefold and greater than threefold induction of luciferase activity respectively when compared with vehicle-treated cells (Fig. 7).

Transfection of GAL4-Smad2 or GAL4-Smad3 with GAL4-Smad4 resulted in noticeable ligand-independent luciferase responses. However, the addition of activin A to the H295R cells transfected with a combination of GAL4Smad2 and GAL4-Smad4 elicited a twofold increase in RLUs when compared with vehicle alone, a response not seen with the GAL4-Smad3/GAL4-Smad4 combination. Inhibin A did not elicit significant increases in transcriptional activity.

Activin A induces up-regulation of the steroidogenic enzyme, P450c17

To determine if activin influences steroidogenesis in H295R cells, the cells were incubated with activin A and inhibin A for $24 \mathrm{~h}$ followed by western analysis to detect P450c17 and P450c21 (Fig. 8A). While no significant increase was seen by densitometric analysis of P450c21, there was a twofold increase over control in the relative intensity of the P450c17 band seen in response to activin. Inhibin induced a similar response in P450c17. The addition of follistatin diminished the P450c17 response to activin (Fig. 8B).

\section{Discussion}

While the exact mechanism of parturition has not been delineated, it is clear that multiple steps and inputs are required for the final process leading to delivery. Characteristically, the key factors in this event are either maternal or fetal in nature. While it is obvious that the placenta and the uterus are vital, it is well recognized that the fetus contributes some cue via an intact HPA axis. In nonprimates such as sheep, overt manipulation of the HPA axis can either result in premature delivery, e.g. by fetal administration of corticosteroids or ACTH, or lack of parturition resulting in the need for cesarean delivery, e.g. after hypophysectomy (Liggins et al. 1973, Antolovich et al. 1991, McDonald \& Nathanielsz 1991).

During gestation, the fetal adrenal gland is exposed to changing vascular and neurological inputs, as well as varied hormonal influences ranging from $\mathrm{ACTH}$ to different growth factors, such as insulin-like growth factor and

Figure 6 Activin and activin receptor activation of reporter gene transcription in H295R cells. All data are expressed as the mean \pm S.D. of triplicate samples from a representative experiment. (A) Activin and type I and type II receptors together mediate transcriptional activation of the p3TP-luc reporter with RII combinations resulting in greater activin stimulated transcription. In all experiments, the total amount of DNA transfected was kept constant. Cells transfected with the p3TP-luc reporter, a Renilla luciferase reporter, and the indicated receptor constructs were cultured with vehicle or activin A at $10 \mathrm{ng} / \mathrm{ml}$ for $24 \mathrm{~h}$ with measurement of relative luciferase activity as described in Materials and Methods. Data were normalized by the ratio of relative firefly luciferase activity to Renilla luciferase activity. H295R cells transfected with the reporters and the empty vector (EV) served as a control. (B) H295R cells produce the $\beta A$ subunit of activin, and follistatin suppresses basal transcriptional activity significantly $(P<0 \cdot 05)$. H295R cells were transfected with the p3TP-luc reporter and incubated with vehicle (control) or with follistatin at $10 \mathrm{ng} / \mathrm{ml}$. The inset shows detection of the $\beta$ A subunit from H295R cells by western analysis with activin A and term amnion as positive controls (Petraglia et al. 1993). (C) Type I receptors mediate ligand-independent transcriptional activation of the p3TP-luc reporter gene. Type II receptors do not. Both types mediate activin-stimulated transcription. H295R cells were transfected with the p3TP-luc reporter and the indicated receptor constructs. Data were normalized to the total amount of protein. The control bar represents luciferase activity after transfection of the reporter alone and incubation with vehicle and activin. Significant differences between the vehicle and activin-treated responses are noted, with statistical analysis as described in Materials and Methods. ${ }^{*} P<0 \cdot 05,{ }^{* *} P<0 \cdot 01$ 
A.

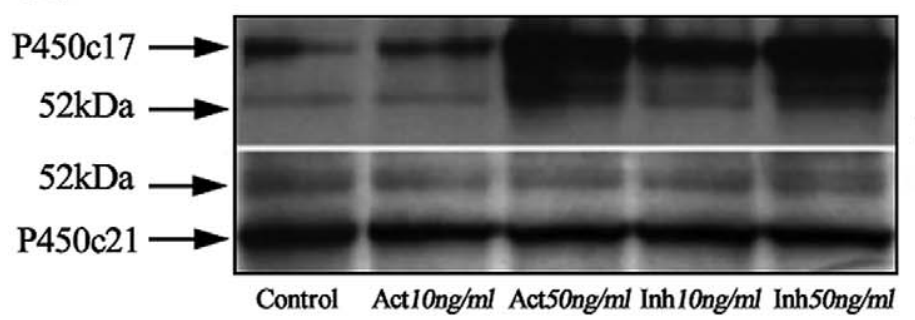

B.

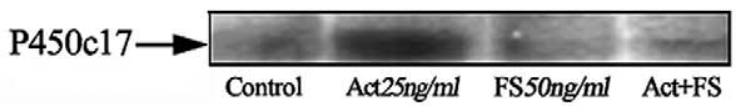

Figure 8 Expression of P450c17 and P450c21, two steroidogenic enzymes crucial for DHEAS and cortisol respectively, in H295R cells in representative western blots. (A) After 24-h treatment with vehicle (control), activin A (Act), or inhibin A (Inh) (at $10 \mathrm{ng} / \mathrm{ml}$ and $50 \mathrm{ng} / \mathrm{ml}$ ), higher concentrations of activin A and inhibin A enhance P450c17 expression (upper panel) by more than twofold over control, an effect not seen with P450c21 (lower panel). (B) Activin increases P450c17 expression in H295R cells, an effect diminished by co-incubation with activin A and follistatin (FS). H295R cells were treated with vehicle, activin A (25 ng/ml), follistatin (50 ng/ml), or activin A and follistatin together for $24 \mathrm{~h}$. Densitometric analysis was performed as described in Materials and Methods.

activin (Mesiano \& Jaffe 1997). Spencer et al. (1992, 1999) examined the effect of activin on primary fetal adrenal cells from second trimester human fetuses. They were able to demonstrate an apoptotic effect on fetal cortical cells by activin as well as augmentation of ACTH-stimulated cortisol production (Spencer et al. 1992, 1999). Given the ability of activin to exert an effect upon these cells, it is reasonable to expect that the known signal transduction cascade for activin should be intact and present in the fetal adrenal gland. While a description of the complement of activin receptors and activin binding proteins has recently been noted in human fetal adrenal glands and the H295R cells (Vanttinen et al. 2002), this study aimed to extend the study of activin signal transduction, focusing on the receptors as well as Smad proteins and their functionality, which had not previously been described.

Given the inherent limitations of working with human fetuses at different gestational ages, the fetal rat adrenal gland and the H295R cell line were chosen as models to validate the hypothesis that the activin signaling cascade is present and active in the fetal adrenal glands. Similar profiles of the receptors and Smads were identified in both the rat adrenals and the H295R cell line at the RNA and protein levels. Evidence of Smad6, Smad7, and SARA mRNA was also identified, which hints at the potential for intracellular regulation of this pathway, e.g. Smad7 can block Smad2 activation and negatively modulate this signaling cascade (Hayashi et al. 1997). The detection of Smad proteins in the whole fetal rat adrenal lysates reflects the endogenous presence of the system in vivo.

Interestingly, age-associated changes were observed for (a) the different type II receptor mRNAs by real-time RT-PCR with increased RIIB mRNA expression in neonatal adrenal glands, and for (b) the Smad4 protein by western analysis with an increased presence with maturation of the organ. The relative expression of the different type II activin receptor subtypes may be important to the resultant activin effect upon a cell, possibly relating to the efficiency of specific activin-responsive gene transcription.
Indirect evidence highlights this possibility. The different staining pattern of RIIB compared with RII may be following a zone-like pattern with less RIIB staining in the subcapsular region, which may correlate with the functional zonation in the fetal rat adrenal cortex, detectable at approximately day 20 by the presence of zone-specific steroidogenic enzymes, such as aldosterone synthase cytochrome P450 at the outermost aspect of the cortex and $11 \beta$-hydroxylase present throughout the cortex earlier in fetal life, but more concentrated in the inner aspect of the cortex after day 20 (Mitani et al. 1999). The real-time RT-PCR data and the pattern of Smad4 expression suggest that RIIB and Smad4 may play a more significant role in the adrenal gland of the neonate. In fetal rat adrenal glands, RII was more abundant, while in the H295R cells, the RIB/RII combination resulted in a greater increase in activin-stimulated transcriptional activity suggesting that RII has relative importance in fetal life in this organ despite the fact that RIIB has a higher affinity for activin than RII (Attisano et al. 1992). This complexity is further extended by the fact that different type I receptors may lead to different responses to the same ligand (Carcamo et al. 1994, Persson et al. 1997), allowing for finely tuned regulation of activin function in multiple types of cells during pregnancy.

Using transient transfections and luciferase assays, transcriptional activity could be examined in relation to different receptors and Smads. The type I receptor easily stimulated transcription when transfected alone with the activin/TGF $\beta$-responsive p3TP-luciferase reporter construct, but overexpression of the type II receptors alone led to a response similar in pattern to that of the type I receptors, but diminished in scale. This implies that type II receptors are available in the cell line to bind the activin (since the type I receptors do not bind activin well (Massague \& Weis-Garcia 1996)), and that despite endogenous production of activin A in the H295R cells (clearly less than that produced in term amnion), there was decreased ligand-independent and ligand-dependent 
stimulation of luciferase activity, which may be related to an unbalanced ratio of type II to type I receptors for receptor complex assembly. While ligand-independent stimulation was also present after co-transfection of type II and type I receptors, combinations with RII showed significant activin responsiveness when compared with those with RIIB. This underscores the potential of activin regulation by the differential effect of the specific receptor subtypes in a dose- or cell-dependent manner based upon cell-specific localization (Attisano et al. 1992) or agespecific expression (Wilson \& Handa 1998). The Smad pathway was specifically targeted with a GAL4 response element luciferase reporter and GAL4-Smad constructs. While ligand-independent transcription was seen with transfection of the receptor GAL4-Smad constructs alone, a robust response resulted after activin exposure, such that with GAL4-Smad2, there was a greater than ninefold increase in luciferase activity. The notable response seen after transfection of the GAL4-Smad2/GAL4-Smad4 and GAL4-Smad3/GAL4-Smad4 combination in the absence of activin revealed that overexpression of these intracellular proteins can lead to transcriptional activity despite the lack of receptor activation.

In addressing possible roles for activin in the fetal adrenal gland, our preliminary studies reveal that steroidogenesis in the adrenal cortex may be impacted. Corroborating Spencer and colleagues' earlier data regarding the augmentation of an ACTH-stimulated effect on the fetal adrenal cells, our immunohistochemistry data illustrated the significant presence of the type II (RII and RIIB) receptor in the cortical regions of the late gestational fetal rat adrenal gland. P450c21 and P450c17, enzymes crucial to the production of corticosteroids and androgens such as cortisol and DHEAS, are localized to these regions and were chosen for study. Interestingly, there was an upregulation of $\mathrm{P} 450 \mathrm{c} 17$ protein expression that appeared dosedependent for both activin A and inhibin A in the H295R cells; the effect on P450c21 was not significant for either activin or inhibin. Actions of inhibin A have frequently been documented as being antagonistic to the actions of activin $A$. In this particular instance, the effect of both activin $\mathrm{A}$ and inhibin $\mathrm{A}$ on $\mathrm{P} 450 \mathrm{c} 17$ are similar, an observation previously noted in the immature porcine Leydig cell (Lejeune et al. 1997). While it is known that inhibin in great excess of activin can bind the activin receptors, there is a developing body of evidence that indicates that complements of receptors on the cell surface, including accessory proteins such as betaglycan, can modulate inhibin A binding to the RIIB2 subtype, thereby altering activin signaling (Chapman et al. 2002), and possibly contributing to the observed effect. Clearly, until more data is available regarding inhibin binding and subsequent intracellular signaling, these inhibin effects will be hard to understand fully. While further investigations are necessary, this steroidogenic effect offers a potential candidate for an activin-responsive gene.
Activin is a pleotropic hormone that probably has both paracrine and endocrine effects in pregnancy. This hypothesis is suggested by the similar gestational pattern of secretion of activin in rodents and humans, and by the evolutionary conservation of its amino acid sequence. However, many of the effects elicited by activin in pregnancy and development have not been fully described or understood. Our findings suggest that the known activin signal transduction pathway acts in the developing adrenal cortex. This pathway's finite effects are likely to include the maturation of this organ via induction of apoptosis of the fetal zone in the primate adrenal cortex, and by the enhancement of ACTH-stimulated cortisol production. Therefore, while identification of the cellular signaling by activin was accomplished in our models, further investigations should be pursued (and when possible with human adrenal glands) to examine the potential of different activin type II receptor isoforms to induce specific cellular responses such as steroid production versus apoptosis, to study the relative importance of varying Smad levels at different points of gestation, and to elucidate specific genes regulated by activin. The methods used in this study can serve as a potential template to investigate the complex roles of activin, both in pregnant and nonpregnant states in other organ systems as well.

\section{Acknowledgements}

We thank K Mayo for the anti-RII and anti-RIIB antisera, Dr Peter ten Dijke for the anti-Smad antibodies, W Miller for the P450c17 antibody and A Payne for the P450c21 antibody. We also thank J Massague for the p3TP-luc reporter plasmid, L Mathews and K Mayo for the activin receptor (type I, IB, II, IIB) expression plasmids, and W Schnaper for the GAL4 response element luciferase reporter and GAL4-Smad constructs. This study was supported by NIH grant HD35708 and the American Association of Obstetricians and Gynecologist Foundation and the Northwestern Memorial Foundation.

\section{References}

Antolovich G, McMillen I, Robinson P, Silver M, Young I \& Perry R 1991 The effect of hypothalamo-pituitary disconnection on the functional and morphologic development of the pituitary adrenal axis in the fetal sheep in the last third of gestation. Neuroendocrinology 54 254-261.

Attisano L, Wrana JL, Cheifetz S \& Massague J 1992 Novel activin receptors: distinct genes and alternative mRNA splicing generate a repertoire of serine/threonine kinase receptors. Cell 68 97-108.

Carcamo J, Weis FM, Ventura F, Wieser R, Wrana JL, Attisano L \& Massague J 1994 Type I receptors specify growth-inhibitory and transcriptional responses to transforming growth factor beta and activin. Molecular and Cellular Biology 14 3810-3821.

Challis JR \& Mitchell BF 1981 Hormonal control of preterm and term parturition. Seminars in Perinatology 5 192-202. 
Chapman S, Bernard D, Jelen J \& Woodruff T 2002 Properties of inhibin binding to betaglycan, InhBP/p120 and the activin type II receptors. Molecular and Cellular Endocrinology 196 79-93.

Chomczynski P \& Sacchi N 1987 Single-step method of RNA isolation by guanidinium thiocyanate-phenol-chloroform extraction. Analytical Biochemistry 162 156-159.

Derynck R, Zhang Y \& Feng X 1998 Smads: transcriptional activators of TGF- $\beta$ responses. Cell 95 737-740.

Draper LB, Chong H, Wang E \& Woodruff TK 1997 The uterine myometrium is a target for increased levels of activin A during pregnancy. Endocrinology 138 3042-3046.

Grobman WA \& Wang EY 2000 Serum levels of activin A and inhibin $\mathrm{A}$ and the subsequent development of preeclampsia. Obstetrics and Gynecology 96 390-394.

Hayashi H, Abdollah S, Qiu Y, Cai J, Xu Y, Grinnell BW, Richardson MA, Topper JN, Gimbrone MA, Wrana JL \& Falb D 1997 The MAD-related protein Smad7 associates with the TGF $\beta$ receptor and functions as an antagonist of TGF $\beta$ signaling. Cell $\mathbf{8 9}$ $1165-1173$.

Imamura $\mathrm{T}$, Takase $\mathrm{M}$, Nishihara $\mathrm{A}$, Oeda E, Hanai J, Kawabata M \& Miyazono K 1997 Smad6 inhibits signalling by the TGF-beta superfamily. Nature 389 622-626.

Lejeune H, Chuzel F, Sanchez P, Durand P, Mather JP \& Saez JM 1997 Stimulating effect of both human recombinant inhibin A and activin A on immature porcine Leydig cell functions in vitro. Endocrinology 138 4783-4791.

Liggins F, Fairclough R, Grieves S, Kendall J \& Knox B 1973 The mechanism of initiation of parturition in the ewe. Recent Progress in Hormone Research 29 111-149.

McDonald T \& Nathanielsz P 1991 Bilateral destruction of fetal paraventricular nuclei prolongs gestation in sheep. American Journal of Obstetrics and Gynecology 165 764-770.

Massague J 1998 TGF-beta signal transduction. Annual Review of Biochemistry 67 753-791.

Massague J \& Weis-Garcia F 1996 Serine/threonine kinase receptors: mediators of transforming growth factor beta family signals. Cell Signaling 27 41-64.

Mesiano S \& Jaffe RB 1997 Role of growth factors in the development regulation of the human fetal adrenal cortex. Steroids $6262-72$.

Mitani F, Mukai K, Ogawa T, Miyamoto H \& Ishimura Y 1997 Expression of cytochromes P450 aldo and P45011 $\beta$ in rat adrenal gland during late gestational and neonatal stages. Steroids 62 57-61.

Mitani F, Mukai K, Miyamoto H, Suematsu M \& Ishimura Y 1999 Development of functional zonation in the rat adrenal cortex. Endocrinology 140 3342-3353.

Muttukrishna S, Knight PG, Groome NP, Redman CW \& Ledger WL 1997 Activin A and inhibin A as possible endocrine markers for pre-eclampsia. Lancet 349 1285-1288.

Muttukrishna S, North RA, Morris J, Schellenberg JC, Taylor RS, Asselin J, Ledger W, Groome N \& Redman CW 2000 Serum inhibin A and activin A are elevated prior to the onset of pre-eclampsia. Human Reproduction 15 1640-1645.

Persson U, Souchelnytskyi S, Franzen P, Miyazono K, ten Dijke P \& Heldin CH 1997 Transforming growth factor (TGF-beta)-specific signaling by chimeric TGF-beta type II receptor with intracellular domain of activin type IIB receptor. Journal of Biological Chemistry 272 21187-21194.

Petraglia F, Woodruff TK, Botticelli G, Botticelli A, Genazzani AR, Mayo KE \& Vale W 1992 Gonadotropin-releasing hormone, inhibin, and activin in human placenta: evidence for a common cellular localization. Journal of Clinical Endocrinology and Metabolism 74 1184-1188.

Petraglia F, Anceschi M, Calza L, Garuti G, Fusaro P, Giardino L, Genazzani A \& Vale W 1993 Inhibin and activin in human fetal membranes: evidence for a local effect of prostaglandin release. Journal of Clinical Endocrinology and Metabolism 77 542-548.

Rainey WE, Bird IM \& Mason JI 1994 The NCI-H295 cell-line: a pluripotent model for human adrenocortical studies. Molecular and Cellular Endocrinology 100 45-50.

Spencer S, Rabinovici J, Mesiano S, Goldsmith P \& Jaffe R 1992 Activin and inhibin in the human adrenal gland: regulation and differential effects in fetal and adult cells. Journal of Clinical Investigation 90 142-149.

Spencer S, Mesiano S, Lee J \& Jaffe R 1999 Proliferation and apoptosis in the human adrenal cortex during the fetal and perinatal periods: implications for growth and remodeling. Journal of Clinical Endocrinology and Metabolism 84 1110-1115.

Tsukazaki T, Chiang TA, Davison AF, Attisano L \& Wrana JL 1998 SARA, a FYVE domain protein that recruits Smad2 to the TGF $\beta$ receptor. Cell 95 779-791.

Vanttinen T, Kuulasmaa T, Liu J \& Voutilainen R 2002 Expression of activin/inhibin receptor and binding protein genes and regulation of activin/inhibin peptide secretion in human adrenocortical cells. Journal of Clinical Endocrinology and Metabolism 87 4257-4263.

Wilson ME \& Handa RJ 1998 Activin subunit, follistatin, and activin receptor gene expression in the prepubertal female rat pituitary. Biology of Reproduction 59 278-283.

Woodruff TK \& Mather JP 1995 Inhibin, activin and the female reproductive axis. Annual Review of Physiology 57 219-244.

Woodruff TK, Sluss P, Wang E, Janssen I \& Mersol-Barg MS 1997 Activin A and follistatin are dynamically regulated during human pregnancy. Journal of Endocrinology 152 167-174.

Zawel L, Dai J, Buckhaults P, Zhou S, Kinzler K, Vogelstien B \& Kern S 1998 Human Smad3 and Smad4 are sequence-specific transcription activators. Molecular Cell 1 611-617.

Received 21 March 2003

Accepted 1 April 2003 